\title{
High performance teams: an investigation of the effect on self-management towards performance
}

\author{
Thais Carreira Pfutzenreuter ${ }^{\mathrm{a} *}$ (D), Edson Pinheiro de Lima ${ }^{\mathrm{a}, \mathrm{b}}$ (D), José Roberto Frega ${ }^{\mathrm{c}}$ \\ aPontifícia Universidade Católica do Paraná, Curitiba, PR, Brasil \\ bUniversidade Tecnológica Federal do Paraná, Pato Branco, PR, Brasil \\ 'Universidade Federal do Paraná, Curitiba, PR, Brasil \\ *thais.pfut@gmail.com
}

\begin{abstract}
Paper aims: Work design is being constantly transformed by technology and requirements for polyvalent workers piloting the work system instead of operating it. This paper investigates self-management teams' implementation and its effects on performance. A Brazilian cosmetics company case study of team development was used as a guidance for this investigation.

Originality: Consistent connection between team development theory and practice, exploring sociotechnical approach and empowerment best practices.
\end{abstract}

Research method: Boxplot analysis is performed over team building stages along with One-way Variance Analysis to test average performance differences among stages' transitions. Tukey test was sequentially applied to identify its statistic differences in pairs. Descriptive analysis and Analysis of Means are complementarily applied for shop-floor accidents performance assessment.

Main findings: Team development reached the expected performance over team stages. Forming to storming, though, was the only transition with no performance average gains. Storming to norming was the highest improvement, which meets sociotechnical principles. Moreover, mean of accidents was inferior at performing stage comparing to the overall mean of accidents during the whole project, highlighting additional shop-floor safety improvements enhanced by the new work design.

Implications for theory and practice: This paper is restricted to a single sociotechnical environment. Therefore, generic conclusions imply further investigation.

\section{Keywords}

Work organization. Team performance. Self-managed teams. Empowerment.

How to cite this article: Pfutzenreuter, T. C., Lima, E. P., \& Frega, J. R. (2021). High performance teams: an investigation of the effect on self-management towards performance. Production, 31, e20210053. https://doi.org/10.1590/01036513.20210053

Received: May 29, 2021; Accepted: Oct. 1, 2021.

\section{Introduction}

According to Alves Filho et al. (1992) Work rationalization, born in the Classical School with Scientific Administration, indorsed critical specification for task execution, and little flexibility in the work posts. Taylor's organizational model consisted of a rigid hierarchy, that it was highly dictating specialized and standardized tasks (Weisbord, 2011; Batiz-Lazo, 2019). The social scientist Elton Mayo was the first to reveal opposition to this work system. Hawthorne Experience, coordinated by the sociologist between 1924 and 1933, showed that Western Electric Company's productivity increased with the stimulus of social aspects in the work environment. Zoller \& Muldoon (2019) comment that the School of Human Relations contradicted Taylor's theory since it knocked down the preponderance of physiologic factors on the psychological ones. Simonetti \& Marx (2010) 
show that Toyota's Japanese approach also brought revolutions when they started to consider the intellectual prospect of working members as a critical success organizational factor.

The models that came after Taylorism started to value the collective work, inside of activities that before were only mechanists. They tried to bring together the projection with the execution of tasks previously segmented by the classical approach. Autonomous teams, however, presented a differentiation factor: the minimization of the hierarchical role figure, stimulating teams for high performance. The sociotechnical model was discovered, and subsequently, studied by Tavistock Institute researchers after observing the productivity's optimization in the English coal mines through self-management in 1949 (Joullié, 2018; Moreira \& Marx, 2008; Marx, 1997; Salerno, 1994).

Lee \& Edmondson (2017) recently investigated current trends and expected benefits that motivate the development of self-managing organizations. Less-hierarchical organizations with employee empowerment initiatives stimulate brighter and faster responses in dynamic conditions. Also, Yin et al. (2018) argue that empowerment has been a mechanism to reduce traditional managing costs and proposed an economic perspective to explain how empowerment practices affect organizational performance indirectly through moderating the effect of the employee-employer exchange relationship.

In sociotechnical work design, as observed by Naikar \& Elix (2021), accounting for the phenomenon of self-organization is critical. Empirical studies reveal that workers in these systems adapt not just their individual behaviors, but also their collective structures. For Manz \& Sims (1996), the work with greater autonomy can increase productivity and work motivation providing competitive advantage for organizations. Salerno (1994) states that the implantation of autonomous teams according to the sociotechnical model, however, involves great and challenging organizational changes. The introduction of these teams requires a new style of leadership and designates greater responsibilities to workers, and not everyone is willing to work in teams. The implementation of these teams is usually of medium to long term and involves high costs, demanding deeper organizational changes and there is not always a consensus between the hierarchies for political changes, as observed by Marx (1997) and Cunningham \& MacGregor (2000). Moreover, Olsson \& Bosch (2018) reinforce that autonomy degrees must be consistent with strategic goals.

Based on the problems related to the organizational challenges of this work model described above, the following research question is proposed for this paper: Can self-managed teams bring exceptional performance improvement? A case study is used as a guidance for this investigation. The case study's company introduced sociotechnical work teams willing to reach high performance and this paper explores its approach with performance improvement over team-building stages. Therefore, this paper presents a meaningful relationship between team empowerment theoretical principles and practice. With the ambition to extend ICPR conference findings (Pfutzenreuter et al., 2021) accident analysis over team building stages was included with the purpose to examine if beyond performance, work design has possibly complementarily enabled a better shop-floor ergonomic environment.

\section{Literature review}

This section explores theoretical background of teams in four dimensions considered relevant to this paper: team building, empowerment, team performance measurement and human factors in Industry 4.0.

\subsection{Team building}

Widely known as an effective team building design for the educational setting (Riebe et al., 2010; Aydin \& Gumus, 2016; Weber \& Karman, 2017), Tuckman approach (1965) remains famous for team development model and it is still known for its four-sequential stages (Kur, 1996; Largent, 2016; Manges et al., 2017). Forming is the first interaction of team members, when they become familiar with each other, concentrating efforts to find out which behaviors are acceptable regarding their tasks, feeling confused on how to act and unsure about the benefits of team participation. There is suspicion, fear and anxiety on the onward work and the common goal supported by the formed team. At storming stage, members start to show resistance and hostility towards each other, occasioning often conflicts caused by miscommunication, what may lead them to disbelief in the collective power. These problems begin to be solved at norming stage, when the whole team effectively learn how to work together and internal differences are overcome. The focus on tasks, interpersonal relationship and mutual identification among members are fortified. Finally, performing stage comes and the responsibility shared is intensified, together with creativity and the expected productivity. Mutual cooperation and team self-identity provide exceptional results (Tuckman, 1965). 
Tuckman \& Jensen (1977) formally extended the original model and added a fifth stage, adjourning, to provide opportunity for acknowledgements. Since then, the model was studied, applied and successfully validated in many team development fields, remaining strongly accepted (Largent, 2016; Aydin \& Gumus, 2016; Manges et al., 2017). An Indonesian research has recently used Tuckman model as a theoretical reference to investigate virtual team performance of Binus University e-learning student's capability of solving teamwork problems (Siregar et al., 2018).

Manges et al. (2017) successfully used the model in the healthcare environment as a guiding framework to improve safe patient care delivery. Nurse leaders' behaviors changed over Tuckman stages and were critical to build high performance teams. At the performing stage, nurse leaders no longer coordinated team actions and focused mainly on empowering members that developed shared leadership in the work design. Kuhrmann \& Münch (2016) highlights Tuckman theory's importance and argue that project managers must be familiar with the theoretical stages because they do not only start during project beginnings, but also when new members join team projects. The authors applied group dynamics with graduate students at Munich Technical University and Blekinge Institute of Technology and reinforced the premise that performance drops after changing teams. Conjointly, the dynamics revealed that time pressure, team size and missing strategies are the factors that mostly impact performance while task complexity and communication aspects affect work efficiency. Additionally, Largent (2016) reinforces Tuckman pattern that team's skill level rises over time and team enthusiasm starts high, drops and then returns to a high level. The author also emphasized the importance of team ability to recognize the team current stage because this awareness can provide knowledge to understand team progress and distinguish between normal and abnormal difficulties along team development.

On the other hand, Tuckman's model was also challenged by some researchers. Kur (1996) complemented that company teams can possibly transit from one stage to another during work execution. Miller (2003) argued that complex teams do not follow the linear team building performance suggested by the psychologist researcher. Rickards \& Moger (2000) also criticized the theoretical model, claiming that not all teams go through all stages. According to the authors, storming stages can possibly never end and teams become dysfunctional, failing to pass a weak behavioral barrier before norming. Even though most teams overcome the weak barrier, fewer teams pass the strong performance one and do not achieve exceptional performance.

A similar model of team development was additionally proposed by Katzenbach \& Smith (1993), projecting a performance curve that losses up to the team complete formation, integration and alignment of the members. Therefore, formation phase will undoubtedly need more time than a group run by a single leader to reach a desirable performance. According to Katzenbach \& Smith (1993) it happens because a real team demands more from its members and team formation phase tends to be less effective. Formation requires difficult adaptation periods in the level of sharing experiences and distinct knowledge among members can bring disagreements and competition. Learning requires trust, as well as trust promotes learning. Therefore, learning and trust are not earned in a short period and only over time inevitable conflicts are solved.

Staniforth (1996) claims that many organizational practices and systems are more aligned to individuals, which inhibits team maturity growth and consequently teamwork performance. Castka et al. (2001) grouped successful factors of high-performance teams implementation into two categories and seven subgroup categories: 1) system factors: organizational impact; alignment and interaction with external entities; performance measures and defined focus 11) human factors: knowledge and skills, individual needs and group culture. The concept of sociotechnical teams reunites both of these technical and social aspects in work design, considering not only the mentioned system factors (Castka et al., 2001), but also the interaction between people and technology during job routine in workplaces, developing essential principles such as responsible autonomy, adaptability, mutual trust and shared leadership for decision making, which leads them to outstanding performance through self-management, differing them from regular teams or small work groups (Marx, 1997; Hess, 2018).

\subsection{Empowerment}

High performance companies depend on internal policies and capabilities (Okoshi et al., 2019; Pinheiro de Lima et al., 2008). Empowerment practices allow coworkers to gather relevant information from each other and prompt employees to work as teammates, which reduces communication and coordination costs. Unlike ineffective authority, autonomy can lead self-managed teams with consistent knowledge shared to make better decisions, contributing to organizational performance and reducing monitoring high costs (Yin et al., 2018).

Idris et al. (2018) found empirical evidence that employee empowerment strengthens job satisfaction for Malaysian capital local workers. Potnuru et al. (2019) recently identified that organizational learning culture remarkably influences the relationships of team building and empowerment on employee competencies in 
Indian cement manufacturing companies. Another interesting finding is the interrelationship between enabling management controls and staff empowerment and their mutual beneficial effects on performance in Australian companies (Baird et al., 2018).

Jian'an (2008) discussed how to build self-management teams through empowerment, proposing pushing and pulling power strategies to achieve the desired dynamic equilibrium between supply and demand of power along team evolution. Empowerment advances gradually with time, maturity and experience, consequently benefits are only obtained in long-term. Strategic guidance is a requirement to optimize business performance through previously established autonomy levels that meets organizational specific ambitions (Olsson \& Bosch, 2018). Autonomy degrees are often low during team forming stage and increases along team life cycle, exerting influence on outcomes (Hess, 2018).

Even though moving away from a traditional hierarchical design is a demand, most organizations persist to inhibit and limit employee's participation and empowerment skills and shifting responsibilities are impossible if leaders at every level are not truly committed to empower their subordinates (Huusko, 2006; Attaran \& Nguyen, 2000; Horner, 1997).

According to Hess (2018) and Brower (1995), hierarchy must be limited to offer only guidelines as well as the confidence required to work execution and autonomous team members' expectations for top leader involvement must be aligned with previously established empowerment degrees consistently further reinforced to ensure perceptions that autonomy given is a real purpose and not purely symbolic.

In order to accelerate autonomy progress, empowerment practices must be adapted. Some approaches are commonly implied, such as training development plans for motivation and knowledge improvement, along with performance assessments connected to the organizational learning programs (Brower, 1995; Holt et al., 2000; Potnuru et al., 2019). Employees' strengths must be intensified instead of focusing on their weaknesses, because complementary team members' skills compensate individual flaws to achieve common goals (Margulies \& Kleiner, 1995). In addition, clear goal statements through effective communication channels are meaningful. Targets and decisions must also be appraised by managers to ensure that commitment and efforts are focused on expected directions. Performance results, acknowledgments and rewards must be afforded not only to individuals, but also to the whole team, to reassure teammates take responsibility for each other's performance. (Brower, 1995; Elmuti, 1997; Conti \& Kleiner, 1997). In conjunction with open and frequent communication, all-inclusive recruitment and consistent resource allocation are other preconditions to be granted to autonomous team members (Hess, 2018).

Knowledge management is one of the most essential elements for successful empowerment projects. In this context, Frank et al. (2018) proposed a systemic vision of the relationship between knowledge transfer factors in product development teams including leadership, organizational culture, individual interests, human and technical skills for strategic team management. Bastos et al. (2019) also reunited a couple of studies on the interplay of organizational and teams design, knowledge management and sharing and human values.

\subsection{Team performance measurement}

Teams with greater autonomy demand performance measurement indicators to appraise autonomy progress and results achieved over time (Marx, 1997). In order to build high performance teams, it is exceedingly indispensable that team members are acquainted and in total consonance with the chosen performance measurement system. According to Aguinis (2013), there are some fundamentals for team performance assessment. Firstly, it is essential to ensure that teams are actually teams sharing common goals and not simply small groups with individual targets. Secondary steps are the investment in measurement structures and clear establishment of performance goals. Further, the selection of multiple appraisal methods focused on processes as well as outcomes and, finally, long-term changes are assessed.

MacBryde \& Mendibil (2003) propose a four-dimensional model for team performance measurement. 1) team effectiveness, the dimension which process' results satisfy team stakeholders; 11) team efficiency, the dimension in which internal processes support the achievement of process outcomes; 111) learning and growth, which consists of monitoring team progress. Some features of this assessment involve transferable skills, documented learning, best practices, tools, methods, process improvement and team innovation potential; IV) satisfaction of the members, which implies motivation and personal fulfillment measurements, quantifying how teamwork contributes to the growth and personal well-being of each teammate.

Work designs, team composition and direct or indirect factors influencing high performance are widely explored by research to support team cohesion theories (Ferreira et al., 2012; Wilsher, 2015; Moura et al., 2019). Rezvani et al. (2019) recently applied partial least square regression analysis on construction project teams' 
surveys to measure emotional intelligence relationship with team performance. Emotional intelligence and trust as a mediate factor were positively related to team performance, while conflict mediate factor presented a negative relation. The study implies that relationship conflicts could be diminished, and trust can be reinforced by improving emotional intelligence to reach performance enhancement. Cha et al. (2014) also used the same statistical methodology with developed surveys based on literature to support member's psychological proximity has a critical effect on team performance.

Jaca et al. (2013) applied a teamwork effectiveness measurement structured by survey to investigate key performance factors employing Input-Mediator-Outcome methodology (llgen et al., 2005; Mathieu et al., 2005). Independence, autonomy, internal leadership, conflict management were some common highly rated and constantly measured in healthcare and manufacturing distinct environments. The relationship between teamwork factors and the process of dynamic capability in service providers were also a research issue and autonomy, integration and cohesion were found meaningful for teamwork in multi-unit service providers (Gonzalez, 2018).

Team performance measurements have been also consistently worked out to test work designs involving leadership styles to evaluate optimizing performance structures. Ciasullo et al. (2017) measured effectiveness, efficiency and satisfaction of members dimensions to compare a traditional top-down with a hybrid bottom-up team building approach. The authors used not only lead-time, an organizational performance indicator, but also applied external and internal surveys to quantify both, customer and employee's satisfaction. Bottom-up team development performed better across all three dimensions of this integrated performance assessment. Yang \& Ok Choi (2009) also identified that empowerment elements influence on team performance through linear regression.

Han et al. (2017) have indirectly explored some dimensions suggested by MacBryde \& Mendibil (2003) in a survey research, testing the effect of shared leadership on team perceived performance. Statistical analysis performed have supported shared leadership indirectly increases performance through stimulating knowledge share, commitment to goals and activity coordination as team mediate factors. Complementary, Müller et al. (2018) have also found that shared leadership positively affects team performance on a laboratory team decisionmaking exercise. Statistical analysis showed not only that sharing leadership brought quality improvement, but also perceived task complexity strengthens this effect. Even with constant complexity, when recognized as harder tasks, shared leadership was intensified and fewer errors were made in work execution.

\subsection{Human factors in Industry 4.0}

Industry 4.0 and technological development have contributed to efficient manufacturing processes and brought new challenges to human work, which occasionally represent a threat to employee well-being, demanding new personal skills and knowledge management. Human factors and ergonomics reunite overall system performance and human well-being in a variety of work structures. Reiman et al. (2021) applied a recent literature review that highlights the immaturity of Industry 4.0 from the perspectives of human factors and ergonomics, reinforcing the need to concentrate efforts on the simultaneous development of technological and human factors capabilities. Some other researchers also agree Industry 4.0 paradigm is turning technologydriven plants into human-centered industrial system. (Longo et al., 2019) and more effort should be expended to design systems capable of evaluating performance efficiency and simultaneously ensure the well-being of human workers. In this context, Tsao et al. (2019) propose the usage of a wearable sensors for human factors and ergonomics assessment and defend the importance to understand how human beings perform in humanmachine systems and what signals should be collected, including behavior and psychophysiological factors to monitor mental and physical workload levels.

Within the conjunction of Industry 4.0 and human factor's scope, an original human factors taxonomy was proposed (Longo et al., 2019) which incorporates all the industrial worker's cognitive capabilities, physical skills, and psychological attitudes with the purpose to establish a correlation between each factor and the workers' performance response in case of an industrial emergency. The method consisted on a Fuzzy Analytic Hierarchy Process analysis in collaboration with experts. Leadership, self-motivation, teamwork, self-confidence, selfassessment and technical knowledge were some of the characteristics that formed the group of factors that are absolutely necessary for exceptional response performance to occasional emergencies. In a similar resource management study, social support, task variety, feedbacks, interdependence, ergonomics, problem solving, work conditions, interactions outside organization and autonomy were some important attributes found that indirectly influence job effects on performance in Colombian workers from different economy sectors (Peiró et al., 2020).

In Industry 4.0 setting, cyber-physical production systems highly depend on human factors and require an integrated system design involving human factors at an early stage. Stern \& Becker (2017) introduced a 
design-to-human factors for cyber-physical production systems, arguing classic job design must go beyond the classic job design that was restricted to light, noise and handling of chemicals and needs to be replaced by work design actions including attractive design, human-adequate tasks with interactive dialogues, mobile workplaces, comprehensible autonomous systems and integration of workers, which meets sociotechnical principles.

In defiance of automation increasement, humans will remain an essential part of operations systems and following this premise (Neumann et al., 2021) a recent framework that enables a systematic assessment of the impacts of Industry 4.0 technology implementation on human workers and system performance was developed and brought evidence relating Industry 4.0 to sociotechnical systems that involve people and the needs of team members must be considered through a system design. Work design needs to acknowledge workers have cognitive, perceptual motor capabilities along with limitations and personal psychosocial needs.

Recent research agenda have also proved human factors value in Industry 4.0 maintenance programs. Darestani et al. (2020) applied fuzzy DEMATEL and ANP techniques for measuring performance factors and concluded employee satisfaction, growth and learning, availability of machinery and equipment, quality of maintenance by the skilled and highly-trained workforce were found the most important factors for a competitive predictive maintenance performance. Guedes et al. (2021) have complementarily investigated the role of teamwork motivation and human factors influence on production lines in a Total Productive Maintenance implementation project and brought consistent evidence of work motivation positive influence on project performance.

\section{Research design}

This paper presents a case study of team building, introduced by a cosmetics Brazilian company with the purpose to reach higher performance with the development of shop-floor self-managed teams. Empowerment practices with technical and behavioral trainings were provided to gradually achieve the desired team autonomy degrees over time. This research consists on measuring quantitative team performance over team building stages and evaluate the team development project, that was segmented by five learning levels. These five progressive stages structured by the company, presented by Figure 1, involved all factory teams and each level was planned to last the period of a year.

The initial stage, called leveling, consisted of math and Portuguese lessons, since the educational level of members is undergraduate, either from high school or elementary degrees. The subsequential stage, forming, gave space for sharing responsibilities among the five members inside each team and skill development through behavioral trainings. At the storming stage, workshops were focused on decision-making and conflict solving for leadership reinforcement, which contributed for norming phase and its following technical trainings. During all team development project, managers gradually left coordination role and started to act as internal consultants and at performing stage, only generic directions were provided together with the confidence for members to accomplish their intended autonomy in work environment. Moreover, an important procedure followed by the company is that, for each stage advancement, besides the mandatory approval after trainings, auditing carried out to reassure that behavioral and professional improvement were successfully achieved to certify team breakthrough.
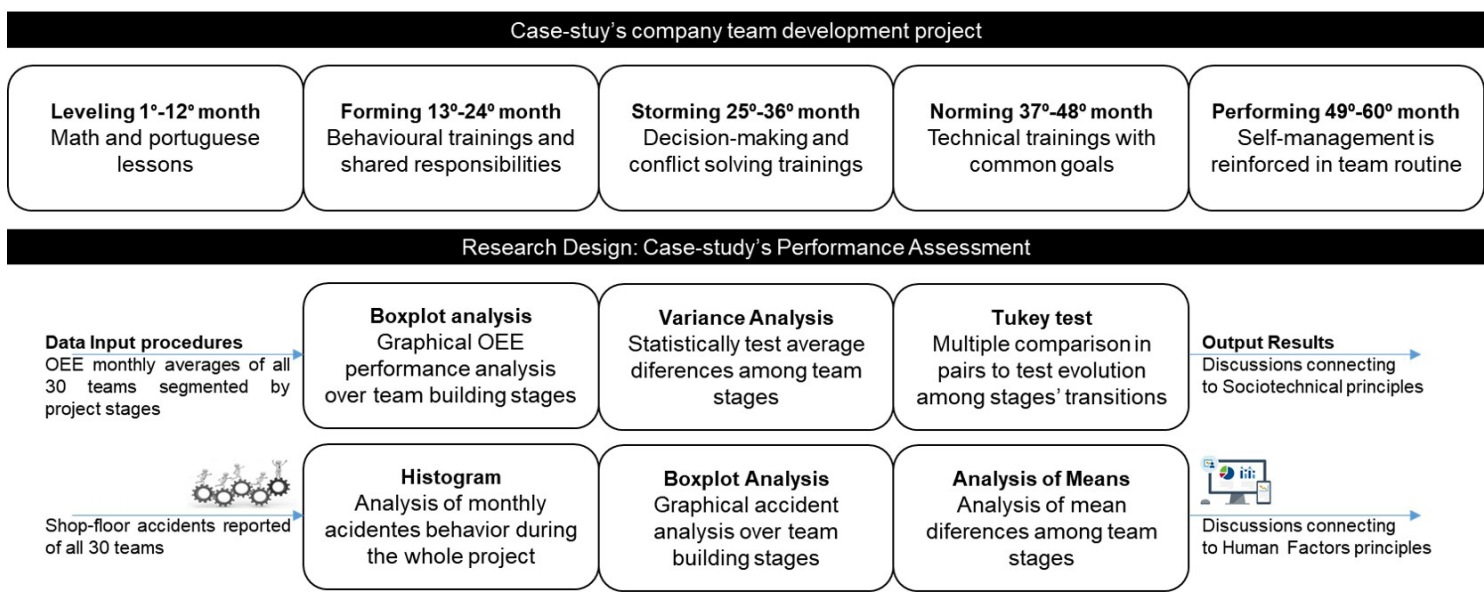

Figure 1. Research design. 
Quantitative performance reports provided by the company managers at the end of the project were the original data source for all the analyses. The main shop-floor performance indicator, overall efficiency, was selected for the assessment. Overall line efficiency is measured by multiplying three target dimensions: availability, performance and quality, which percentages are respectively decomposed by Equation 1 . This measure provides an assessment of how well a manufacturing operation is performed compared to its full potential, calculating actual over scheduled working time (availability percentage), at the real cycle time speed over target (performance percentage), considering only good quality production volume over total production (quality percentage).

$$
\text { Overall Efficiency }=\frac{\text { Actual working time }}{\text { Scheduled working time }} \times \frac{\text { Real cycletime }}{\text { Target cycletime }} \times \frac{\text { Good quality production volume }}{\text { Total ProductionVolume }}
$$

Since the purpose is generic conclusions, team performance data of all 30 developed teams, were converted to monthly performance averages as a single team for all the following analyses described below.

1. Boxplot with all stages of overall efficiency's performance in a single chart was applied to graphically analyze performance over team learning stages;

2. One-way variance analysis was applied to statistically test performance average differences among team stages;

3. Tukey test was applied to test overall efficiency's multiple comparison in pairs to test performance evolution analysis between stages' transitions.

With the purpose to extend findings to Industry 4.0 and human factors context, accident analysis indicator was also assessed. Accident analysis, presented by Equation 2, a discrete variable measured through the number of accidents monthly reported in the factory, was collected for the following steps.

$$
\text { Number of accidents }=\text { Count of monthly accidents }
$$

4. Histogram analysis was initially performed to investigate accidents behavior during the whole team development project;

5. Boxplot analysis was applied to graphically analyze accident occurrences over team stages;

6. Analysis of Means was performed to examine mean differences among team stages.

The performance assessment exhibited by Figure 1 was applied to evaluate performance enhancement with the new intended work design and consequently answer the research proposed question regarding the ability of self-managing teams to bring high performance and a better ergonomic scenario in work environment.

\section{Results}

Overall efficiency exhibits wide-ranging performance evolution over the stages, presented by Figure 2. 1t is perceptible forming to storming is the only particular distinguishable transition that did not present considerable difference in the average values. Performance staunchly had its greatest increase at storming to norming and repeatedly had another breakthrough at performing stage, when overall efficiency data is more concentrated, reaching persistent performance stability.

Performance behavior presented in boxplot reinforces some literature principles further explored in discussion section. Boxplot method provided graphical evolution overview, summarizing each stage's enhancement along team development. A single-factor variance analysis for overall efficiency was sequentially appropriate to test significant average difference among stages. Table 1 details the hypothesis test, performed with 95\% confidence interval for this analysis.

Before conclusions, test premises were challenged. Since residues showed a large adherence to the standard normal distribution and residual variances were approximately equal, premises were ratified. Considering a 95\% confidence level, HO was rejected, since $\mathrm{p}$-value $<0.05$. Therefore, statistical evidence of significant average difference for at least a couple of overall efficiency's stages was found. Tukey's test was then conveniently useful to test average differences between stages in pairs, presented by Figure 3.

By means of the 95\% confidence interval for differences between averages, Tukey's test showed that only forming to storming stage had no significant difference, as suspected upon boxplots descriptive analysis. In addition, it also implied a respective improvement for all the other transitions compared in pairs since the 


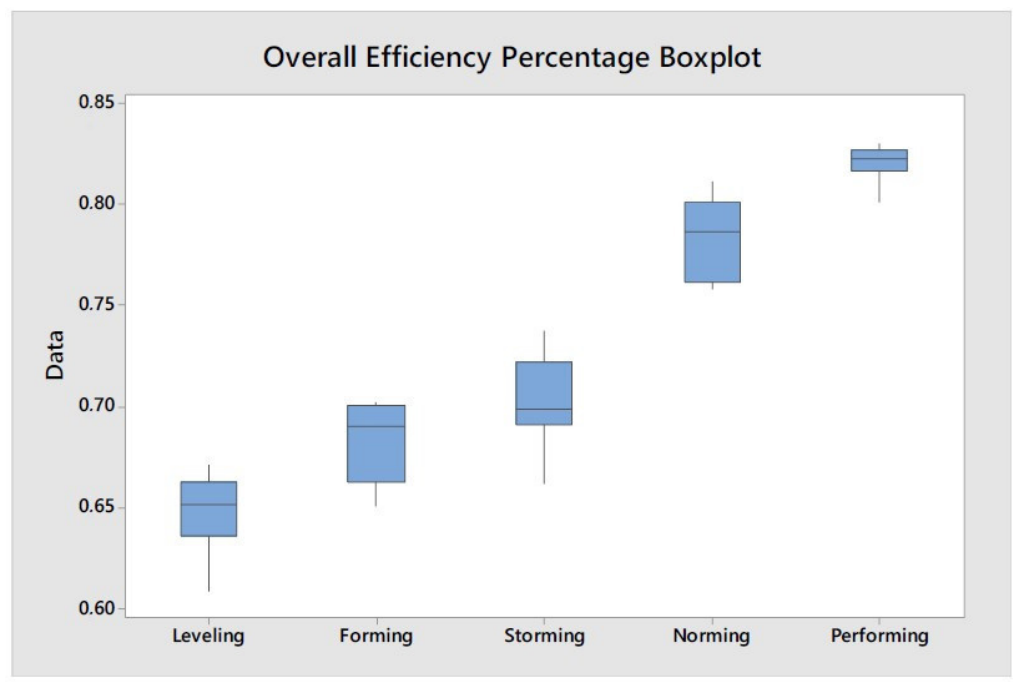

Figure 2. OEE Boxplot analysis.

Table 1. Hypothesis test.

\begin{tabular}{|c|c|c|c|c|c|}
\hline \multicolumn{6}{|c|}{ Method } \\
\hline \multicolumn{6}{|c|}{ Null hypothesis All Means are equal } \\
\hline \multicolumn{6}{|c|}{ Alternative hypothesis Not all means are equal } \\
\hline \multicolumn{6}{|c|}{ Significance level $\alpha=0.05$} \\
\hline \multicolumn{6}{|c|}{ Equal variances were assumed for the analysis. } \\
\hline \multicolumn{6}{|c|}{ Factor Information } \\
\hline Factor & Levels & \multicolumn{4}{|c|}{ Values } \\
\hline Factor & 5 & \multicolumn{4}{|c|}{ Leveling; Forming; Storming; Norming; Performing } \\
\hline \multicolumn{6}{|c|}{ Analysis of Variance } \\
\hline Source & DF & Adj SS & Adj MS & F-Value & P-Value \\
\hline Factor & 4 & 0.24884 & 0.06221 & 184.25 & 0.000 \\
\hline Error & 55 & 0.01857 & 0.000338 & & \\
\hline Total & 59 & 0.26741 & & & \\
\hline
\end{tabular}

DF: Degrees of Freedom; SS: Sum of Squares; MS: Mean Square; F-Value: Adj MS Factor over Adj MS Error; P-value: Area to the right of Fk-1, n-k.

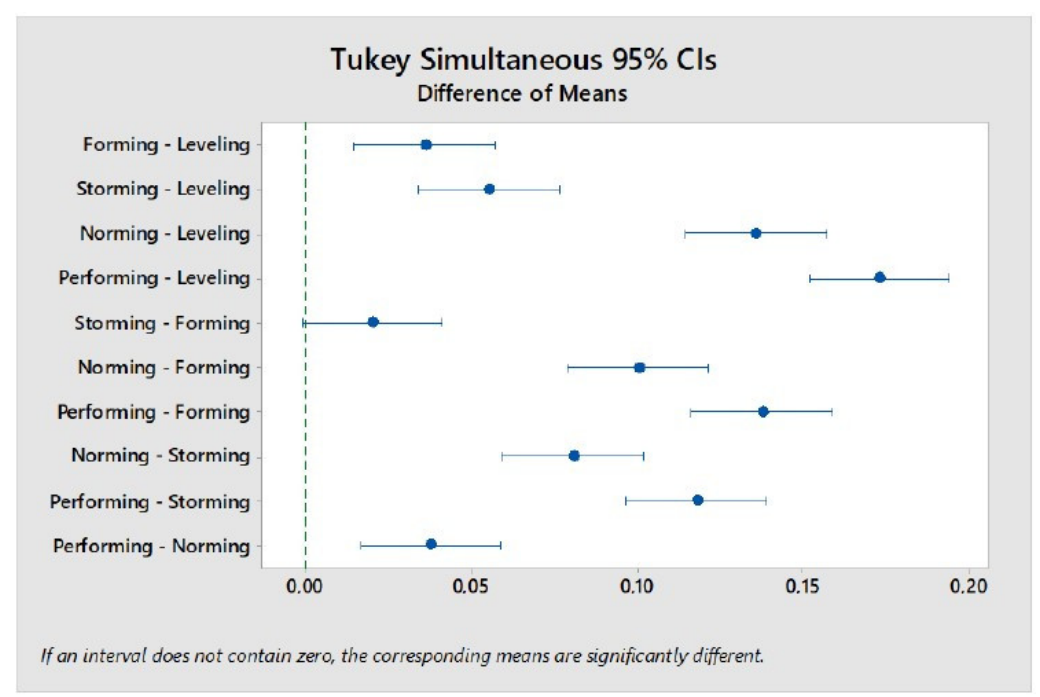

Figure 3. Tukey test. 
difference is always positive, hence, it essentially diagnoses overall efficiency gain over all other transitions, except forming-storming.

In order to extend OEE performance improvement assessment, the number of accidents among team development project was complementarily inspected with descriptive analysis. Figure 4 presents accidents descriptive analysis. Histogram presents the numbers of accidents during the whole project, without any team level distinction. It reveals during 20 of the 60 months of team building program the number of accidents consisted of two accidents monthly. Reuniting the 17 occurrences of a single accidents and 6 months with no unexpected events, it can be highlighted that more than $70 \%$ of the project months the total of monthly accidents was under two, which seems a good insight considering a company with more than three thousand shop-floor workers.

Boxplot analysis, also exhibited by Figure 4, complements introducing the behavior of accidents among team development stages. It is perceptible storming to norming was a remarkable improvement. Although it had a specific bad month performance of four accidents, it represents an outlier single event that may also have specific reasons depending on the norming training moment. The number of accidents is not only more advantageous at performing level, but data is also more concentrated, which is a meaningful improvement for the self-managed teams, that reached a stable work environment with less frequent casualties. It is interesting to identify accident analysis matches OEE performance boxplot analysis, since both of them revealed good improvements on storming to norming transition and a subsequential outstanding achievement at performing.
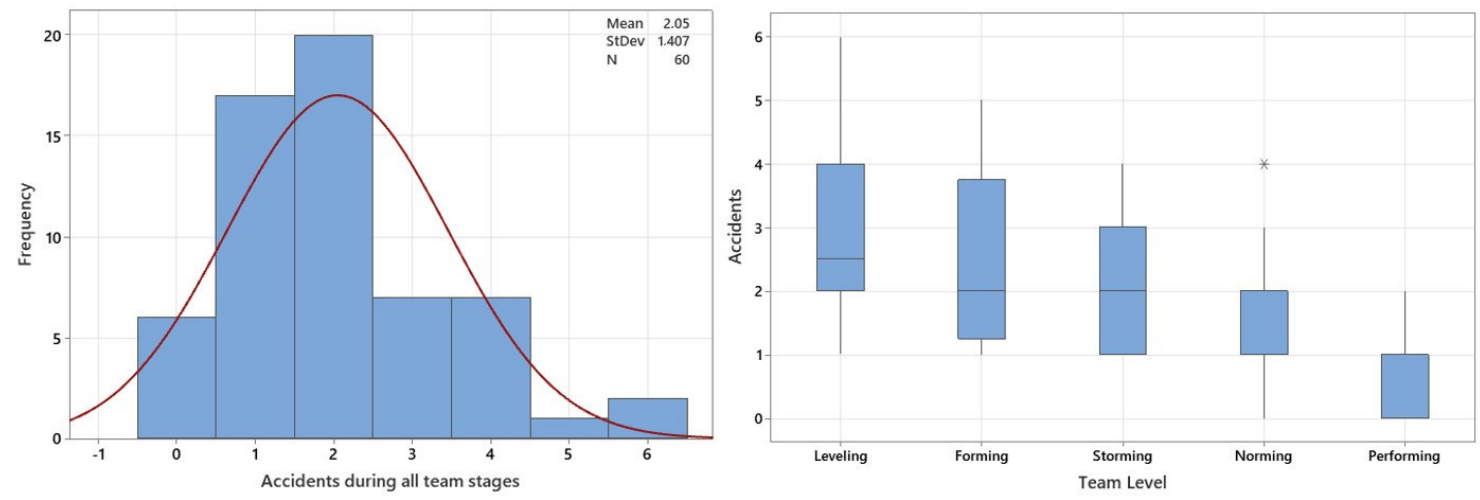

Figure 4. Number of accidents descriptive analysis.

Analysis of means is a graphical alternative to ANOVA that tests the equality of population means. The graph displays each factor level mean, the overall mean, and the decision limits. If a point falls outside the decision limits, then evidence exists that the factor level mean represented by that point is significantly different from the overall mean.

ANOVA tests whether the treatment means differ from each other while ANOM tests whether the treatment means differ from the overall mean, also called the grand mean. Considering the practical graphical analysis and interpretability, ANOM test was selected to perform Accidents Analysis of Means.

Analysis of Means, exhibited by Figure 5, indicates there is evidence that both leveling and performing stages present means significantly different from the overall mean at $\alpha=0.05$. Since forming is above the upper decision limit, it is possible to assume leveling has a mean of accidents significantly above 2.05, the grand mean. On the other hand, performing mean of accidents is under the lower decision limit, presenting a significant lower mean compared to the overall mean.

Moreover, it is essential to highlight that although it graphically illustrates a fall in the mean of accidents over all team building stages, forming, storming and norming mean of accidents do not present significant mean difference from the grand mean at $\alpha=0.05$. However, storming to norming represents an important transition since norming is the first stage under the overall mean of accidents, even being this difference not statistically significant. 
One-Way Normal ANOM for ACCIDENTS

$\alpha=0.05$

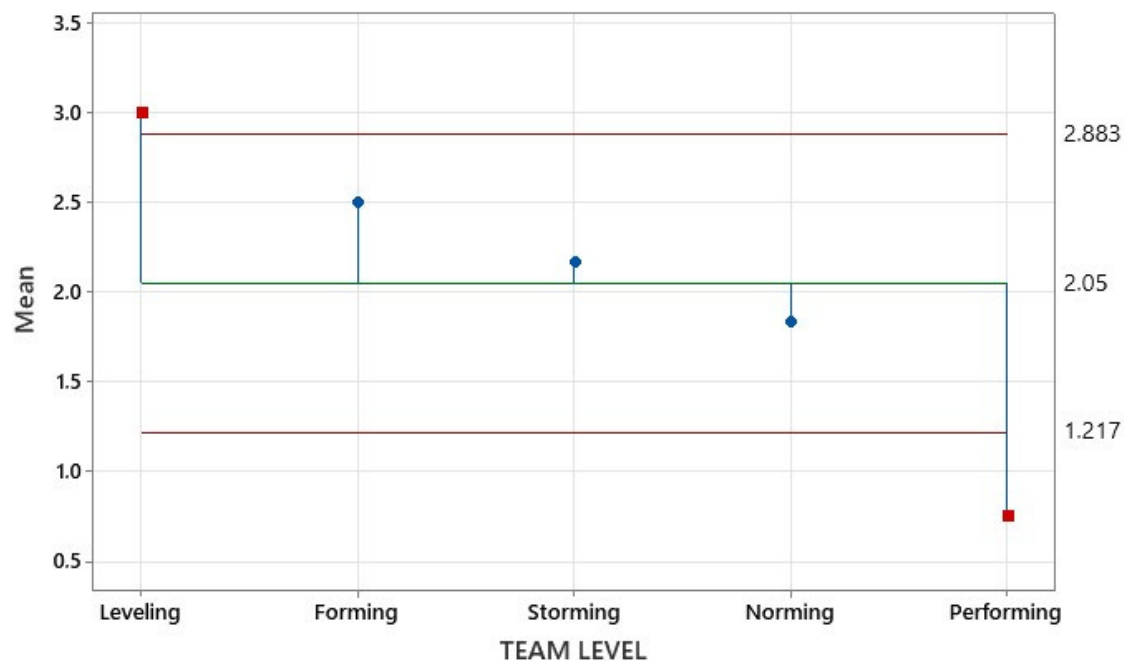

Figure 5. Accidents analysis of means.

\section{Discussion}

The training development approach adopted by the company to introduce team development matches Tuckman's initial model (1965). The autonomy given was previously planned to attend organizational demands as highlighted in literature by Olsson \& Bosch (2018) and autonomy was initially low (Hess, 2018). Both initial Boxplot and Variance Analysis approaches imply performance improvement along team autonomy progress.

Boxplot presented consistent performance breakthrough over team development, even though some stage transitions noticeably had different improvement scales. Although there was no performance loss from forming to storming as defended by theory (Tuckman, 1965; Katzenbach \& Smith, 1993), it was the only transition with no performance average gains since Tukey's test showed no significant average differences between both stages. Storming to norming is highlighted by Tuckman theory as the greatest performance evolution, which also coincides with the case study's pattern. The highest improvement also corresponds to Katzenbach and Smith's theory (1993), that implies a huge evolution from potential team to real team. Tukey's test analysis also implies that teams have succeeded at passing both, weak behavioral and strong performance barriers, suggested by Rickards \& Moger (2000).

Salerno (1994), Manz \& Sims (1996), and Simonetti \& Marx (2010) emphasized that self-managed teams, besides performance gains and commitment improvement, also reduces processes variability, which was an achieved result by the teams, since performing stage presented consistent lower variability in Boxplot analysis. Accident analysis performance assessment matches OEE performance boxplot analysis, since both of them revealed good improvements on storming to norming transition and a subsequential outstanding achievement at performing and both reinforced team development theories (Tuckman, 1965; Katzenbach \& Smith, 1993).

Learning and growth and team efficiency are some of the dimensions suggested by MacBryde \& Mendibil (2003) related and explored in this case study. Team development brought the high-performance expectation achievement in the long-term defended by sociotechnical researchers (Moreira \& Marx, 2008). 1t is essential to recognize that empowerment practices applied are related to theoretical principles, such as training programs, open communication and shared leadership with previously designed individual responsibilities (Brower, 1995; Margulies \& Kleiner, 1995; Hess, 2018).

This study also implies theoretical discussion related to future approaches of organizational work. Salerno (1994) defends that despite the autonomy given for decision-making during work execution, teams cannot be regarded as completely autonomous, after all even with great empowerment, members can't be completely independent since they belong to an organization with strategies of its own. However, Zarifian (1997) believes that this tends to change in the future, because according to the author, it is not possible to keep two management systems built on different principles for too long. Self-organizations do not only reduce coordination costs 
(Yin et al., 2018) but remain studied because they also respond more effectively in dynamic scenarios (Lee \& Edmondson, 2017).

This paper supports sociotechnical approach principles, bringing evidence that the case study's company achieved its ambition to reach high performance with the new work design with empowered teams (Salerno, 1994; Marx, 1997). Empowerment benefits remarkably appeared in the long-term, as implied by researchers (Jian'an, 2008; Olsson \& Bosch, 2018). This study suggests that a team building prosperity has a connection to empowerment practices that meets literature suggestions (Margulies \& Kleiner, 1995; Elmuti, 1997; Brower, 1995) such as internal alignment between managers and teams (Hess, 2018) and proper strategic guidance before team development to gradually introduce autonomy (Olsson \& Bosch, 2018).

Sociotechnical approach has also dialogued to human factors recent studies in Industry 4.0 and therefore literature review brought recent findings supporting there are no engineering systems without humans (Neumann et al., 2021). Humans cannot be re-engineered, so designs must be made to suit them and emergent technologies have been contributing to human-centered industrial systems (Longo et al., 2019). Moreover, cyber-physical production systems highly depend on human factors and imply investments on attractive design and comprehensible autonomous systems with teamwork integration (Stern \& Becker, 2017), which are also connected to self-management requirements that were contemplated by the project of the investigated case-study.

Work design in Industry 4.0 needs to acknowledge workers have personal capabilities, psychological demands and limitations (Neumann et al., 2021). In Industry 4.0 scenario, organizations need to align their skills to internal ergonomics and provide autonomy, social support, feedbacks, problem-solving workshops for interactions and knowledge management (Bastos et al., 2019; Frank et al., 2018; Peiró et al., 2020). These key-factors highlighted by human factors research in Industry 4.0 have been incorporated by the company in the trainings for the team-building project and results have shown not only overall efficiency performance gains, but also a reduction in shop-floor accidents, increasing safety in work environment.

\section{Conclusion}

This paper strengthens the hypothesis that self-managed teams can reach high performance, since quantitative analysis showed performance evolution on the presented case study, and positively answered the research investigative proposed question. Team building academic contributors and sociotechnical researchers provided a strong theoretical background, making it possible to connect theory to practice identifying similarities and divergences shown in the discussion section. The consistency of this integration brings relevance and originality to this paper in work organizational field.

Accident analysis over team building stages revealed work design has additionally enabled a better shop-floor ergonomic environment, with a reduction in accidents at performing stage mean comparing to the overall mean of accidents during the whole project. This complementary finding is also essential and directly related not only to sociotechnical principles, but also to human factors in Industry 4.0 principles, building an interconnection among all these theoretical fields.

Limitations are also relevant to direct following research to cover some topics left unexplored in the present case study. For this reason, cost-exchange perspective must be a further study, to quantify managing costs reduction brought by empowerment practices defended by literature and examine the investment made on training programs comparing to team development's cost reduction. It is equally important to emphasize that we do not generalize and extend our conclusions to other realities because the present study was restricted to a single company case-study.

This paper is mainly focused on measuring team performance across team development, exploring learning and growth versus team efficiency dimensions. The unexplored dimensions could be further assessed by internal surveys to measure employee's satisfaction individually and inside their own teams, together with external surveys to evaluate customer satisfaction, as explored by team building research present in the visited literature. Complimentarily, empowerment measurement itself through external questionnaires along with internal learning and shared leadership mediate factors' influence on performance could be meaningful techniques to extend our case study's analysis.

Statistical analysis presented in research design were applied using team performance averages for general conclusions. Consequently, a further study exploring teams individually could also contribute to additional and more specific studies. It is also suggested the Myers-Briggs Type Indicator test application for team building and leadership development. Based on the ideas of analytical psychology, the test provides individual personality analysis and their behavior in different situations, considering specific preferences, values and motivations. 
Therefore, another complementary research involving members' personalities inside teams could be also an interesting following theme to test relations between team personality structure and performance.

\section{References}

Aguinis, H. (2013). Performance management (3rd ed). Boston: Pearson.

Alves Filho, A. G., Marx, R., \& Zilbovicius, M. (1992). Fordismo e novos paradigmas de produção: questões sobre a transição no Brasil. Production, 2(2), 113-124. http://dx.doi.org/10.1590/S0103-65131992000200001.

Attaran, M., \& Nguyen, T. T. (2000). Creating the right structural fit for self-directed teams. Team Performance Management, 6(1-2), 25-33. http://dx.doi.org/10.1108/13527590010731952.

Aydin, l. E., \& Gumus, S. (2016). Sense of classroom community and team development. Turkish Online Journal of Distance Education, 17(1), 60-77. http://dx.doi.org/10.17718/tojde.09900.

Baird, K., Su, S., \& Munir, R. (2018). The relationship between the enabling use of controls, employee empowerment, and performance. Personnel Review, 47(1), 257-274. http://dx.doi.org/10.1108/PR-12-2016-0324.

Bastos, F. D., Cordeiro, J. V., \& Drohomeretski, E. (2019). Human values, teamwork design and knowledge management on the shop floor: a systematic literature review. Independent Journal of Management \& Production, 10(1), 186. http://dx.doi.org/10.14807/ ijmp.v10i1.795.

Batiz-Lazo, B. (2019). What is new in "a new history of management”? Journal of Management History, 25(1), 114-124. http://dx.doi. org/10.1108/JMH-07-2018-0033.

Brower, M. J. (1995). Empowering teams: what, why, and how. Empowerment in Organizations, 3(1), 13-25. http://dx.doi. org/10.1108/09684899510079780.

Castka, P., Bamber, C. J., Sharp, J. M., \& Belohoubek, P. (2001). Factors affecting successful implementation of high performance teams. Team Performance Management, 77-8), 123-134. http://dx.doi.org/10.1108/13527590110411037.

Cha, M., Park, J. G., \& Lee, J. (2014). Effects of team member psychological proximity on teamwork performance. Team Performance Management, 20(1), 81-96. http://dx.doi.org/10.1108/TPM-03-2013-0007.

Ciasullo, M. V., Cosimato, S., Gaeta, M., \& Palumbo, R. (2017). Comparing two approaches to team building: a performance measurement evaluation. Team Performance Management, 23(7-8), 333-351. http://dx.doi.org/10.1108/TPM-01-2017-0002.

Conti, B., \& Kleiner, B. H. (1997). How to increase teamwork in organizations. Training for Quality, 5(1), 26-29. http://dx.doi. org/10.1108/09684879710156496.

Cunningham, J. B., \& MacGregor, J. (2000). Trust and the Design of work complementary constructs in satisfaction and performance. Human Relations, 53(12), 1575-1591. http://dx.doi.org/10.1177/00187267005312003.

Darestani, S. A., Ganji, M., \& Imannezhad, R. (2020). What are the key determinants of maintenance performance? Production, 30, e20190155. http://dx.doi.org/10.1590/0103-6513.20190155.

Elmuti, D. (1997). The perceived impact of team- based management systems on organizational effectiveness. Team Performance Management, 3(3), 179-192.

Ferreira, P. G. S., Lima, E. P., \& da Costa, S. E. G. (2012). Perception of virtual team's performance: a multinational exercise. International Journal of Production Economics, 140(1), 416-430. http://dx.doi.org/10.1016/j.jpe.2012.06.025.

Frank, A. G., Ayala, N. F., Corso, M., \& Ribeiro, J. L. D. (2018). A relationship model for factors influencing knowledge transfer between NPD teams. Production, 28, e20180055. http://dx.doi.org/10.1590/0103-6513.20180055.

Gonzalez, R. V. D. (2018). Dynamic capability: an analysis in multi-unit service providers. Production, 28, e20180046. http://dx.doi. org/10.1590/0103-6513.20180046.

Guedes, M., Figueiredo, P. S., Pereira-Guizzo, C. S., \& Loiola, E. (2021). The role of motivation in the results of total productive maintenance. Production, 31, e20200057. http://dx.doi.org/10.1590/0103-6513.20200057.

Han, S. J., Lee, Y., Beyerlein, M., \& Kolb, J. (2017). Shared leadership in teams. Team Performance Management, 24(3-4), 150-168. http://dx.doi.org/10.1108/TPM-11-2016-0050.

Hess, J. P. (2018). Autonomous team members' expectations for top-leader involvement. Team Performance Management, 24(5-6), 283-297. http://dx.doi.org/10.1108/TPM-10-2017-0060.

Holt, G. D., Love, P. E. D., \& Jawahar Nesan, L. (2000). Employee empowerment in construction: an implementation model for process improvement. Team Performance Management, 6(3-4), 47-51. http://dx.doi.org/10.1108/13527590010343007.

Horner, M. (1997). Leadership theory: past, present and future. Team Performance Management, 3(4), 270-287. http://dx.doi. org/10.1108/13527599710195402.

Huusko, L. (2006). The lack of skills: an obstacle in teamwork. Team Performance Management, 12(1-2), 5-16. http://dx.doi. org/10.1108/13527590610652756.

Idris, A., See, D., \& Coughlan, P. (2018). Employee empowerment and job satisfaction in urban Malaysia. Journal of Organizational Change Management, 31(3), 697-711. http://dx.doi.org/10.1108/J0CM-04-2017-0155.

Ilgen, D. R., Hollenbeck, J. R., Johnson, M., \& Jundt, D. (2005). Team in organizations: from input-process-output models to IM01 models. Annual Review of Psychology, 56(1), 517-543. http://dx.doi.org/10.1146/annurev.psych.56.091103.070250. PMid:15709945.

Jaca, C., Viles, E., Tanco, M., Mateo, R., \& Santos, J. (2013). Teamwork effectiveness factors in healthcare and manufacturing industries. Team Performance Management, 19(3), 222-236. http://dx.doi.org/10.1108/TPM-06-2012-0017.

Jian'an, C. (2008). Research on strategies and empowerment process to achieve self-management team. In Proceedings of the 2008 International Conference on Wireless Communications, Networking and Mobile Computing, WiCOM 2008 (pp. 1-5). USA: IEEE. http://dx.doi.org/10.1109/WiCom.2008.1731. 
Joullié, J. E. (2018). Management without theory for the twenty-first century. Journal of Management History, 24(4), 377-395. http:// dx.doi.org/10.1108/JMH-05-2018-0024.

Katzenbach, J. R., \& Smith, D. (1993). The Wisdom of teams: creating the high-performance organization. Boston: Harvard Business School Press.

Kuhrmann, M., \& Münch, J. (2016). When teams go crazy: An environment to experience group dynamics in software project management courses. Proceedings - International Conference on Software Engineering, 412-421. http://dx.doi.org/10.1145/2889160.2889194.

Kur, E. (1996). The faces model of high performing team development. Management Development Review, 9(6), 25-35. http://dx.doi. org/10.1108/09622519610151624.

Largent, D. L. (2016). Measuring and understanding team development by capturing self-assessed enthusiasm and skill levels. $A C M$ Transactions on Computing Education, 16(2), 1-27. http://dx.doi.org/10.1145/2791394.

Lee, M. Y., \& Edmondson, A. C. (2017). Self-managing organizations: exploring the limits of less-hierarchical organizing. Research in Organizational Behavior, 37, 35-58. http://dx.doi.org/10.1016/j.riob.2017.10.002.

Lima, E. P., Costa, S. E. G., \& Angelis, J. J. (2008). The strategic management of operations system performance. International Journal of Business Performance Management, 10(10), 108-132. http://dx.doi.org/10.1504/1JBPM.2008.015924.

Longo, F., Nicoletti, L., \& Padovano, A. (2019). Modeling workers' behavior: a human factors taxonomy and a fuzzy analysis in the case of industrial accidents. International Journal of Industrial Ergonomics, 69, 29-47. http://dx.doi.org/10.1016/j.ergon.2018.09.002.

MacBryde, J. C., \& Mendibil, K. (2003). Designing performance measurement systems for teams: theory or practice. Management Decision, 14(8), 722-733. http://dx.doi.org/10.1108/00251740310496233.

Manges, K., Scott-Cawiezell, J., \& Ward, M. M. (2017). Maximizing team performance: the critical role of the nurse leader. Nursing Forum, 52(1), 21-29. http://dx.doi.org/10.1111/nuf.12161. PMid:27194144.

Manz, C. C., \& Sims, H. P. (1996). Empresas sem chefes. São Paulo: Makron Books.

Margulies, J. S., \& Kleiner, B. H. (1995). New designs of work groups: applications of empowerment. Empowerment in Organizations, 3(2), 12-18. http://dx.doi.org/10.1108/09684899510089284.

Marx, R. (1997). Autonomia, trabalho em grupo e estratégia empresarial. 0 que há de novo neste final de século? São Paulo em Perspectiva, 11(4), 67-75.

Mathieu, J. E., Heffner, T. S., Goodwin, G. F., Cannon-Bowers, J. A., \& Salas, E. (2005). Scaling the quality of teammates' mental models: equifinality and normative comparisons. Journal of Organizational Behavior, 26(1), 37-56. http://dx.doi.org/10.1002/job.296.

Miller, D. L. (2003). The stages of group development: a retrospective study of dynamic team processes. Canadian Journal of Administrative Sciences, 20(2), 121-134. http://dx.doi.org/10.1111/j.1936-4490.2003.tb00698.x.

Moreira, L. F. C., \& Marx, R. (2008). Evolução da organização do trabalho fabril: aplicação do modelo de semi-autonomia em empresa nacional de cosméticos. In Anais do XXVIII Encontro Nacional de Engenharia de Produção. Rio de Janeiro: ABEPRO.

Moura, 1., Dominguez, C., \& Varajão, J. (2019). Information systems project teams: factors for high performance. Team Performance Management, 25(1-2), 69-83. http://dx.doi.org/10.1108/TPM-03-2018-0022.

Müller, E., Pintor, S., \& Wegge, J. (2018). Shared leadership effectiveness: perceived task complexity as moderator. Team Performance Management, 24(5-6), 298-315. http://dx.doi.org/10.1108/TPM-09-2017-0048.

Naikar, N., \& Elix, B. (2021). Designing for self-organisation in sociotechnical systems: resilience engineering, cognitive work analysis, and the diagram of work organisation possibilities. Cognition Technology and Work, 23(1), 23-37. http://dx.doi.org/10.1007/ s10111-019-00595-y.

Neumann, W. P., Winkelhaus, S., Grosse, E. H., \& Glock, C. H. (2021). Industry 4.0 and the human factor - A systems framework and analysis methodology for successful development. International Journal of Production Economics, 233, 107992. https://doi. org/10.1016/j.jpe.2020.107992.

Okoshi, C. Y., Pinheiro de Lima, E., \& Gouvea Da Costa, S. E. (2019). Performance cause and effect studies: analyzing high performance manufacturing companies. International Journal of Production Economics, 210, 27-41. http://dx.doi.org/10.1016/j.ijpe.2019.01.003.

Olsson, H. H., \& Bosch, J. (2018). Singing the praise of empowerment: or paying the cost of chaos. In Proceedings - 44th Euromicro Conference on Software Engineering and Advanced Applications (SEAA) USA: IEEE. http://dx.doi.org/10.1109/SEAA.2018.00012.

Peiró, J. M., Bayona, J. A., Caballer, A., \& Di Fabio, A. (2020). Importance of work characteristics affects job performance: the mediating role of individual dispositions on the work design-performance relationships. Personality and Individual Differences, 157, 109808. http://dx.doi.org/10.1016/j.paid.2019.109808.

Pfutzenreuter, T. C., de Lima, E. P., \& Frega, J. R. (2021). Building high performance teams. In D. A. Rossit, F. Tohmé \& G. Mejía Delgadillo (Eds.), Production Research. ICPR-Americas 2020. Communications in Computer and Information Science (Vol. 1407). Cham: Springer. http://dx.doi.org/10.1007/978-3-030-76307-7_19.

Potnuru, R. K. G., Sahoo, C. K., \& Sharma, R. (2019). Team building, employee empowerment and employee competencies: moderating role of organizational learning culture. European Journal of Training and Development, 43(1-2), 39-60. http://dx.doi.org/10.1108/ EJTD-08-2018-0086.

Reiman, A., Kaivo-oja, J., Parviainen, E., Takala, E. P., \& Lauraeus, T. (2021). Human factors and ergonomics in manufacturing in the industry 4.0 context - A scoping review. Technology in Society, 65, 101572. http://dx.doi.org/10.1016/j.techsoc.2021.101572.

Rezvani, A., Barrett, R., \& Khosravi, P. (2019). Investigating the relationships among team emotional intelligence, trust, conflict and team performance. Team Performance Management, 25(1-2), 120-137. http://dx.doi.org/10.1108/TPM-03-2018-0019.

Rickards, T., \& Moger, S. (2000). Creative leadership processes in a project team. British Journal of Management, 11(4), 273-283. http:// dx.doi.org/10.1111/1467-8551.00173.

Riebe, L., Roepen, D., Santarelli, B., \& Marchioro, G. (2010). Teamwork: effectively teaching an employability skill. Education + Training, 52(6), 528-539. http://dx.doi.org/10.1108/00400911011068478.

Salerno, M. S. (1994). Mudança organizacional e trabalho direto em função de flexibilidade e perfomance da produção industrial. Production, 4(1), 5-22. http://dx.doi.org/10.1590/S0103-65131994000100001. 
Simonetti, P. E., \& Marx, R. (2010). Estudo sobre implementação de trabalho em grupos com autonomia: pesquisa quantitativa numa amostra de empresas operando no Brasil. Production, 20(3), 347-358. http://dx.doi.org/10.1590/S0103-65132010005000051.

Siregar, C., Pane, M. M., \& Ruman, Y. S. (2018). The virtual team performance in solving teamwork conflict problems. In ICDEL '18: Proceedings of the 2018 International Conference on Distance Education and Learning (pp. 1-5). http://dx.doi.org/10.1145/3231848.3231850

Staniforth, D. (1996). Teamworking, or individual working in a team? Team Performance Management, 2(3), 37-41. http://dx.doi. org/10.1108/13527599610126256.

Stern, H., \& Becker, T. (2017). Development of a model for the integration of human factors in cyber-physical production systems. Procedia Manufacturing, 9, 151-158. http://dx.doi.org/10.1016/j.promfg.2017.04.030.

Tsao, L., Li, L., \& Ma, L. (2019). Human work and status evaluation based on wearable sensors in human factors and ergonomics: a review. IEEE Transactions on Human-Machine Systems, 49(1), 72-84. http://dx.doi.org/10.1109/THMS.2018.2878824.

Tuckman, B. W. (1965). Developmental sequence in small groups. Psychological Bulletin, 63(6), 384-399. http://dx.doi.org/10.1037/ h0022100. PMid:14314073.

Tuckman, B. W., \& Jensen, M. A. C. (1977). Stages of small-group development revisited. Group \& Organization Management, 2(4), 419-427. http://dx.doi.org/10.1177/105960117700200404.

Weber, M. D., \& Karman, T. A. (2017). Student group approach to teaching using Tuckman model of group development. The American Journal of physiology, 261(6), S12-S16. http://dx.doi.org/10.1152/advances.1991.261.6.S12. PMid:1755475.

Weisbord, M. (2011). Taylor, McGregor and me. Journal of Management History, 172), 165-177. http://dx.doi.org/10.1108/17511341111112578.

Wilsher, S. (2015). Behavior profiling: implications for recruitment and team building. Strategic Direction, 31(9), 1-5. http://dx.doi. org/10.1108/SD-02-2015-0023.

Yang, S.-B., \& Ok Choi, S. (2009). Employee empowerment and team performance: autonomy, responsibility, information, and creativity. Team Performance Management, 15(5-6), 289-301. http://dx.doi.org/10.1108/13527590910983549.

Yin, Y., Wang, Y., \& Lu, Y. (2018). Why firms adopt empowerment practices and how such practices affect firm performance? A transaction cost-exchange perspective. Human Resource Management Review, 29(1), 111-124. http://dx.doi.org/10.1016/j.hrmr.2018.01.002.

Zarifian, P. (1997). Organização e sistema de gestão: à procura de uma nova coerência. Gestão \& Produção, 4(1), 76-87. http://dx.doi. org/10.1590/S0104-530X1997000100004.

Zoller, Y. J., \& Muldoon, J. (2019). Illuminating the principles of social exchange theory with Hawthorne studies. Journal of Management History, 25(1), 47-66. http://dx.doi.org/10.1108/JMH-05-2018-0026. 